\title{
Cytogenetic studies on Mepraia gajardoi (Heteroptera: Reduviidae). Chromosome behaviour in a spontaneous translocation mutant
}

\author{
Ruben PÉREZ ${ }^{1}$, Lucia CALlEROS ${ }^{1}$, Virginia ROSE ${ }^{1}$, Myriam LORCA ${ }^{2}$ and Francisco PANZERA ${ }^{1}$ \\ ${ }^{1}$ Sección Genética Evolutiva, Departamento de Biología Animal, Instituto de Biología, Facultad de Ciencias, Iguá 4225, 11400 \\ Montevideo, Uruguay; e-mail: rperez@fcien.edu.uy \\ ${ }^{2}$ Departamento de Parasitología, Facultad de Medicina, Universidad de Chile, P.O. Box 33052-33, Las Palmeras 299, Santiago de \\ Chile, Chile
}

Key words. Heteroptera, Triatominae, Mepraia gajardoi, holocentric chromosome, autosomal translocation

\begin{abstract}
We analysed the chromosome complement and male meiosis in a natural population of Mepraia gajardoi (Hemiptera: Reduviidae: Triatominae). The normal karyotype of this species is 20 autosomes plus $\mathrm{X}_{1} \mathrm{X}_{2} \mathrm{Y}$ in males and $\mathrm{X}_{1} \mathrm{X}_{1} \mathrm{X}_{2} \mathrm{X}_{2}$ in females. We confirmed that M. gajardoi is cytogenetically strikingly different from M. spinolai (with which it was previously included), which supports the taxonomic separation of these two species. For the first time in the holocentric chromosomes of the subfamily Triatominae, a structural rearrangement was detected. Observations made during meiosis and mitosis indicated that one of eleven individuals had undergone a fusion between two non-homologous chromosomes, probably before germinal cell development. This autosomal translocation resulted in chromosomal irregularities such as an autosomal trivalent, autosomal univalents and chromosomal fragments, which altered the normal segregation of both autosomes and sex chromosomes. The chromosomal fragments resemble supernumerary or B chromosomes, which supports the idea that these chromosomes are remnants of structural rearrangements. The genetic consequences of translocations in holokinetic chromosomes and their role in the evolution of chromosomes in triatomines are also discussed.
\end{abstract}

\section{INTRODUCTION}

The Heteroptera, or true bugs, include many species of economical and medical importance. Among them, the subfamily Triatominae is particularly relevant because most of their members are vectors of the protozoan Trypanosoma cruzi, causative agent of Chagas disease or American trypanosomiasis. This parasitic disease is one of the most important in the tropics and subtropics of the Americas, with about 200,000 cases per year (WHO, 2002). Owing to their medical importance, the Triatominae have been subject to many genetic studies (Dujardin et al., 2002). Chromosome studies have been used for species differentiation (Pérez et al., 1992), detection of intraspecific variation (Panzera et al., 1992) and to establish the evolutionary relationships of several species (Panzera et al., 1995; 1997; Pérez et al., 2002).

Triatomines are also of particular cytogenetic interest because they have holocentric chromosomes characterised by the presence of a diffuse or non-localised centromere (Hughes-Schrader \& Schrader, 1961). There is little information on the evolution of chromosomes in organisms with holocentric chromosomes because of the difficulty of detecting structural variation, due to the lack of a morphologically differentiated centromere and the scarcity of longitudinal chromosomal differentiation. For these reasons chromosome rearrangements, such as inversions and reciprocal translocations, are rarely reported in Heteroptera (Toledo-Piza, 1944; Papeschi \& Mola, 1990; Bressa et al., 1998). In Triatominae, no chromosomal rearrangement has been reported in any of the 70 cytogenetically described species (Dujardin et al., 2002). As a consequence, mainly the behaviour of chromosomes during meiosis and C-banding patterns are used to evaluate divergence and chromosomal evolution in the Triatominae (Pérez et al., 2002).

In the present study the chromosomal complement and male meiosis in a natural population of Mepraia gajardoi are described. Of the males studied, one showed meiotic irregularities that involved two autosomal pairs. Here normal and altered meiotic behaviour are described and compared, and it is suggested that the abnormalities are the consequence of an autosomal translocation (fusion). The meiotic segregation and genetic consequences of translocations in holocentric chromosomes are analysed and their potential role in the chromosome evolution of Triatominae discussed.

\section{MATERIALS AND METHODS}

Material
Mepraia gajardoi inhabits arid and sub-arid costal regions of
northern Chile (Regions I and II) where it is the principal vector
of Trypanosoma cruzi. Adult specimens were collected in the
mornings and evenings in February 2002, in the town of Arica
(Region I) around the Military History Museum on the Arica
promontory. Eight males and three females were collected for
this study. A distinctive morphological characteristic of this spe-
cies is alary polymorphism: all males are macropterous and
females micropterous. Gonial mitosis was studied in both sexes,
but meiosis can only be studied in males.

\section{Cytogenetic studies}

Gonads (testes and ovaries) were removed from freshly killed adults, fixed in an ethanol-acetic acid mixture $(3: 1)$ and stored at $-20^{\circ} \mathrm{C}$. Air-dried chromosome preparations were made by 


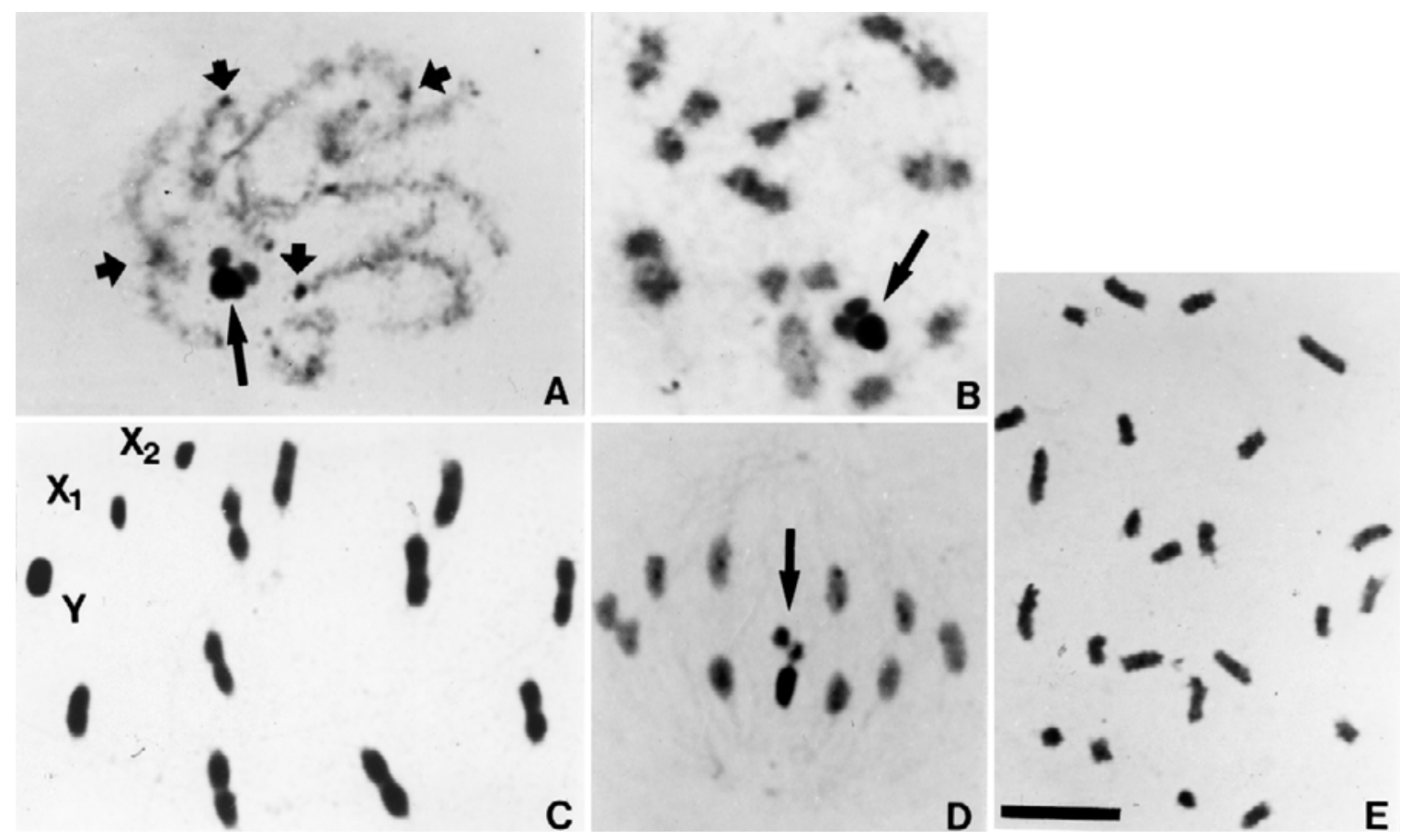

Fig. 1. Mepraia gajardoi. C-banding and meiotic behaviour in normal individuals. $2 \mathrm{n}=20$ Autosomes plus $\mathrm{X}_{1} \mathrm{X}_{2} \mathrm{Y}$ in males $/ \mathrm{X}_{1} \mathrm{X}_{1} \mathrm{X}_{2} \mathrm{X}_{2}$ in females. Bar $=10 \mu \mathrm{m}$. A-D - Male meiosis. A - Pachytene. The three sex chromosomes are heteropycnotic and associated with each other (large arrow). Small terminal C-bands are present on some autosomal bivalents (small arrows). B - Diakinesis. Sex chromosomes remain associated (large arrow). There is only one chiasma per autosomal bivalent. C - First meiotic metaphase. There are only small differences in the sizes of the ten autosomal bivalents. The sex chromosomes do not pair with each other and remain entirely separate; they segregate equationally during the following anaphase. The $\mathrm{X}$ chromosomes are the smallest of the complement. The Y chromosome is completely C-heterochromatic, while the X chromosomes are euchromatic. D - Second metaphase. The ten half bivalents form a ring-shape configuration on the equatorial plate with the three sex chromosomes in the centre. This spatial disposition is characteristic of all triatomine species. The sex chromatids $\left(\mathrm{Y}, \mathrm{X}_{1}\right.$ and $\left.\mathrm{X}_{2}\right)$ are associated at this stage (heterologous association), which allow them to segregate at anaphase. In the second anaphase the $\mathrm{X}$ chromatids move to one pole and the $\mathrm{Y}$ to the other. Therefore, this division is reductional for the sex chromosomes, as in other Hemiptera. E - Oogonial mitotic prometaphase. Twenty-four chromosomes can be observed. X chromosomes are the smallest of the complement.

squashing gonads in 50\% acetic acid, freezing them in liquid nitrogen and removing the coverslip with a razor blade. Chromosome preparations were stained for C-banding as described by Pérez et al. (1997) and examined using a Nikon Microphot FX microscope and photographs were taken using Kodalith 25 film.

\section{RESULTS}

\section{Karyotype and meiosis in the normal individuals}

The normal male diploid chromosome complement in M. gajardoi consists of 23 chromosomes $(2 \mathrm{n}=20 \mathrm{~A}+$ $\mathrm{X}_{1} \mathrm{X}_{2} \mathrm{Y}$ ). Some autosomes have telomeric C-dots, which appear scattered throughout the nucleus during early meiotic prophase (Fig. 1A). Autosomal bivalents apparently have only one terminal or subterminal chiasma during diplotene and diakinesis (Fig. 1B). The sex chromosomes are positively heteropycnotic and lie close to each other. The Y chromosome appears totally heterochromatic and the $\mathrm{X}$ chromosomes euchromatic (Fig. 1B). At first metaphase the ten autosomal bivalents and three sex univalents are easily identified (Fig. 1C). Autosomal bivalents gradually decrease in size, with the $\mathrm{X}$ chromosomes the smallest of the set (Fig. 1C). At first anaphase, sex chromosomes divide equationally. Second metaphase follows immediately after first telophase, without an intervening interkinesis stage. At second metaphase, the autosomes form a ring along the equatorial plane with the associated $\mathrm{X}$ and $\mathrm{Y}$ chromatids at the centre (arrow Fig. 1D). In second anaphase the $\mathrm{X}$ chromatids migrate to one pole and the $\mathrm{Y}$ chromatid to the other.

Gonial mitosis of females indicates a diploid chromosome number of 24 chromosomes consisting of 20 autosomes and four sex chromosomes $\left(\mathrm{X}_{1} \mathrm{X}_{1} \mathrm{X}_{2} \mathrm{X}_{2}\right)$ (Fig. 1E).

\section{Meiosis in the mutant individual}

Among the eight males of $M$. gajardoi, seven had a normal karyotype and one a different chromosomal complement in which the two autosomes were replaced by one large chromosome $\left(2 \mathrm{n}=19 \mathrm{~A}+\mathrm{X}_{1} \mathrm{X}_{2} \mathrm{Y}\right)$ (Figs 2A, B). This single large chromosome probably originated from a simple unequal translocation (fusion) between two nonhomologous chromosomes (Fig. 2C). This hypothesis is confirmed by an analysis of the meiotic behaviour and chromosome segregation. During the first division, $90 \%$ of the cells (54 out of 60) had a chromosome complement of eight bivalents, one trivalent and three sex chromosomes $\left(\mathrm{X}_{1}, \mathrm{X}_{2}\right.$ and $\mathrm{Y}$ ) (Fig. 3). The trivalent always had two chiasmata during diplotene and diakinesis (Fig. 3A) and at first metaphase was clearly made up of three chromosomes (arrows Figs 3B-D). In 9\% of first metaphase 

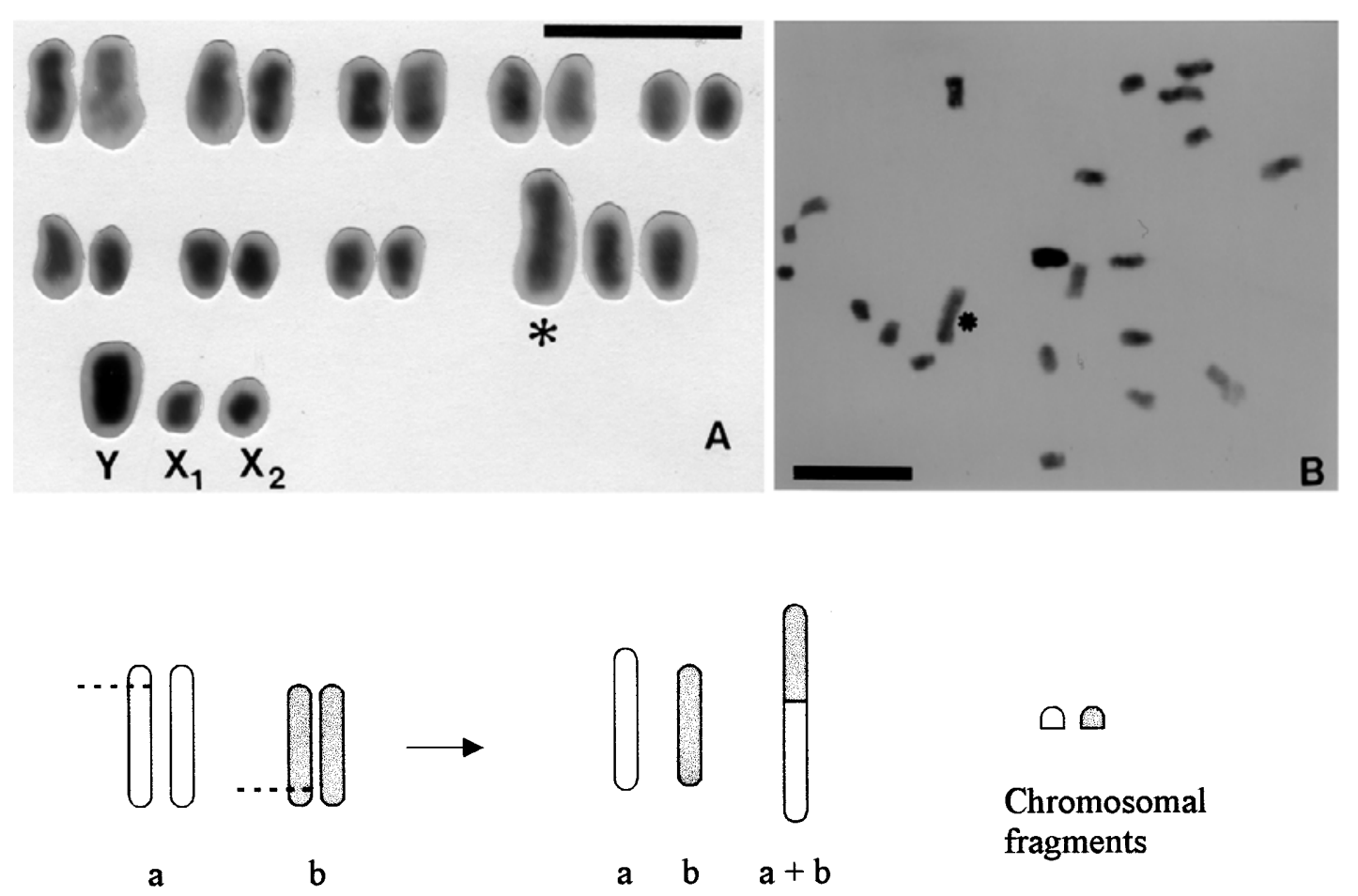

C

Fig. 2. Mepraia gajardoi. Mitotic karyotype of the mutant individual (male). $2 \mathrm{n}=22$ chromosomes (19 A plus $\left.\mathrm{X}_{1} \mathrm{X}_{2} \mathrm{Y}\right)$. $\mathrm{Bar}=10$ $\mu \mathrm{m}$. A - C-banding karyotype. One of the autosomes is larger than the rest (asterisk). This large chromosome originated by the fusion of two non-homologous chromosomes. B - Spermatogonial mitotic prometaphase used to determine the karyotype. The asterisk indicates the fused chromosome. $\mathrm{C}$ - Schematic representation of the supposed translocation (fusion) between two chromosomes of different autosomal pairs: $\mathrm{a}$ - homologues chromosomes of one pair; $\mathrm{b}$ - homologues chromosomes of the other pair; $\mathrm{a}+\mathrm{b}$ - fused chromosome. The autosomal translocation also produces chromosomal fragments that persist in some cells.

plates, a bivalent and a univalent (an unpaired chromosome) were present instead of a trivalent (Fig. 3E). Moreover, in one cell there were three univalents rather than a trivalent (arrowhead Fig. 3F). When univalents are present they lie at the center of the ring formed by the autosomes, near the sex chromosomes (Fig. 3F).

During late metaphase, the trivalent had a "tripod" shape with one chromosome facing one pole and the other two the opposite pole (arrow Fig. 3D). This suggests a reductional division during first anaphase, which is sup-

TABLE 1. Number of different chromosomal complement observed at the second metaphase in the cells of a mutant individual of Mepraia gajardoi. A - autosomes, I - univalent.

\begin{tabular}{lc}
\hline \multicolumn{1}{c}{ Chromosomal complement } & No. of cells observed \\
\hline $10 \mathrm{~A}+\mathrm{XXY}$ & 144 \\
$10 \mathrm{~A}+\mathrm{X}$ & 2 \\
$10 \mathrm{~A}+\mathrm{XX}$ & 1 \\
$10 \mathrm{~A}+\mathrm{XY}$ & 1 \\
$10 \mathrm{~A}+\mathrm{XXY}+1 \mathrm{I}$ & 6 \\
$10 \mathrm{~A}+\mathrm{XXY}+2 \mathrm{I}$ & 5 \\
$10 \mathrm{~A}+\mathrm{XXY}+3 \mathrm{I}$ & 1 \\
$9 \mathrm{~A}+\mathrm{XXY}$ & 179 \\
9 A + YYX & 2 \\
$9 \mathrm{~A}+\mathrm{YYXX}$ & 2 \\
9 A + XXY + I & 26 \\
$9 \mathrm{~A}+\mathrm{XXY}+2 \mathrm{I}$ & 5 \\
$8 \mathrm{~A}+\mathrm{XXY}$ & 1 \\
$8 \mathrm{~A}+\mathrm{XXY}+\mathrm{I}$ & 2 \\
$8 \mathrm{~A}+\mathrm{XXY}+2$ I & 1 \\
\hline
\end{tabular}

ported by the analysis of the second metaphase. The $1: 2$ separation of the trivalent at first anaphase results in two different chromosome complements at the second metaphase: $10 \mathrm{~A}+\mathrm{X}_{1} \mathrm{X}_{2} \mathrm{Y}$ (Fig. $4 \mathrm{~A}$ ) and $9 \mathrm{~A}+\mathrm{X}_{1} \mathrm{X}_{2} \mathrm{Y}$ (Fig. $4 B)$. In addition, other abnormal metaphase plates were also observed at a low frequency (see Table 1). These unusual second metaphases exhibited a large range of abnormalities, including the presence of variable numbers of autosomes (from eight to ten) and univalents (Figs 4C, D). The univalents (single chromatids) usually lie near the sex chromosomes and resemble an extra X chromosome. The number of sex chromosomes may also be affected since some second metaphase plates have fewer sex chromatids (Table 1) while others have an extra Y chromosome (Fig. 4E).

Another irregularity detected in the mutant was the extra very small chromosomes or chromosomal fragments, which exhibited negative pycnosis (arrowheads Fig. 4F). These chromosomes varied in number or were absent in some cells. At the first meiotic metaphase, $40 \%$ of the cells (24 out of 60 ) had either one $(17 / 24)$ (arrowhead Fig. 3C), two (6/24) or three (1/24) chromosomal fragments. At the second metaphase, $19 \%$ of the cells (71 out of 380$)$ had either one $(55 / 71)$, two (14/71) (arrowheads Fig. 4F) or three (2/71) chromosomal fragments. Variable numbers of these extra chromosomes were also observed at meiosis. 


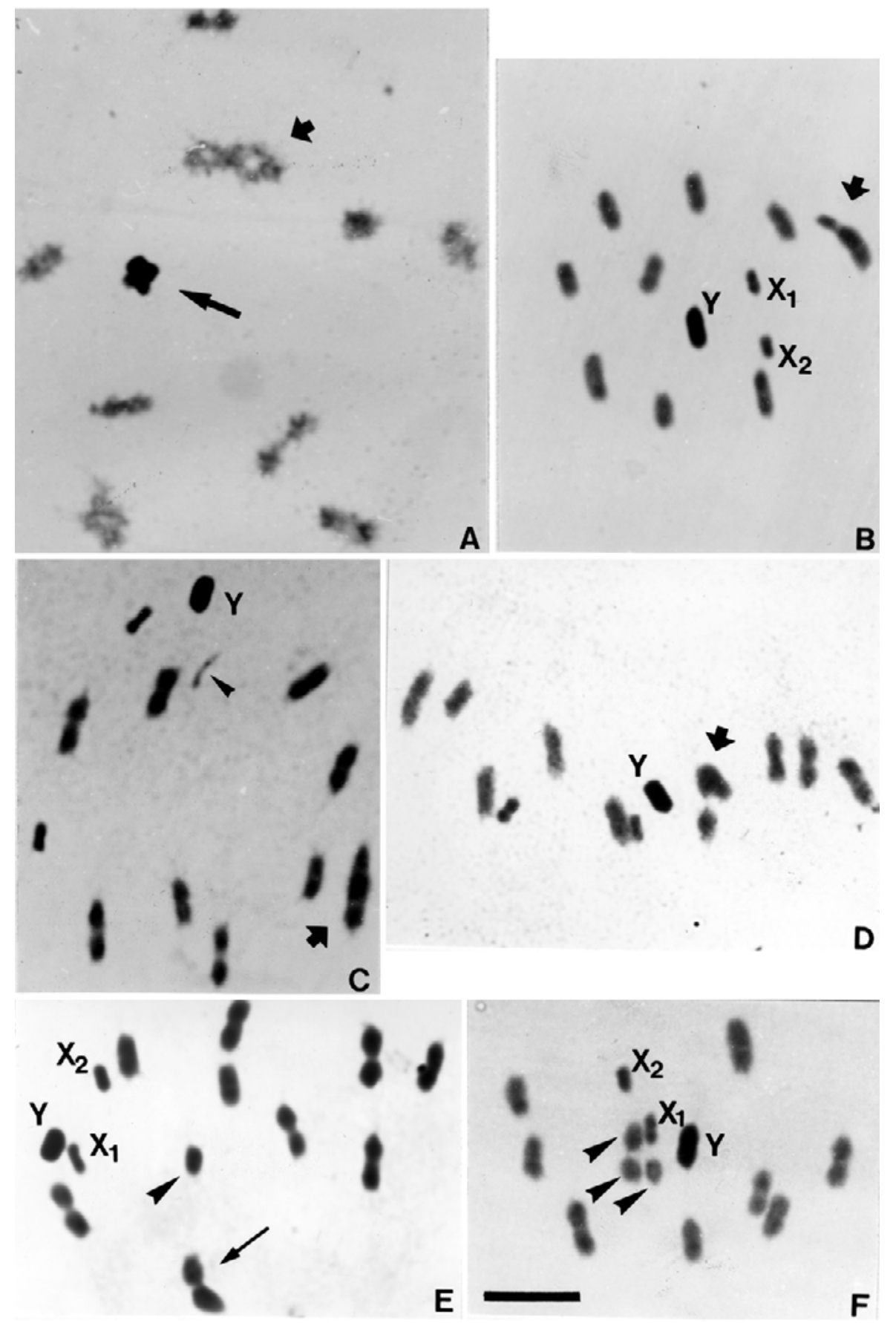

Fig. 3. Mepraia gajardoi. First meiotic division in the mutant individual (male). C-banding technique. Bar $=10 \mu \mathrm{m}$. A Diplotene. Sex chromosomes are closely associated in a chromocenter (large arrow). There are eight autosomal bivalents, each with one chiasma, and an autosomal trivalent with two chiasmata (small arrow). B-F - First metaphase plates. All of them with $\mathrm{X}_{1} \mathrm{X}_{2} \mathrm{Y}$ sex chromosomes. B - Eight autosomal bivalents are present. Small arrow indicates an autosomal trivalent. The Y chromosome is $\mathrm{C}$-heterochromatic and the $\mathrm{X}$ chromosomes euchromatic. $\mathrm{C}$ - Besides eight autosomal bivalents and one trivalent (arrow), a small chromosome fragment is also present (arrowhead). D - The "tripod" shape of the trivalent suggest there will be a $2: 1$ segregation in the subsequent anaphase I (arrow). E - This metaphase plate has eight normal bivalents, one heteromorphic bivalent (arrow) and one univalent (arrowhead). F - Eight bivalents and three autosomal univalents (arrowheads) are present. The univalents are close to the sex chromosomes.

\section{DISCUSSION}

\section{Cytogenetics of Mepraia gajardoi}

Originally considered as a population of Mepraia (= Triatoma) spinolai, M. gajardoi is now ranked as a distinct species (Frías et al., 1998; Jurberg et al., 2002).
The chromosome number and the C-banding of the normal specimens studied are similar to those described for other populations by Frías et al. (1998). Mepraia gajardoi has the following distinctive cytogenetic features: small C-bands on a few autosomal pairs, euchromatic $\mathrm{X}$ chromosomes and a meiotic chromocenter 


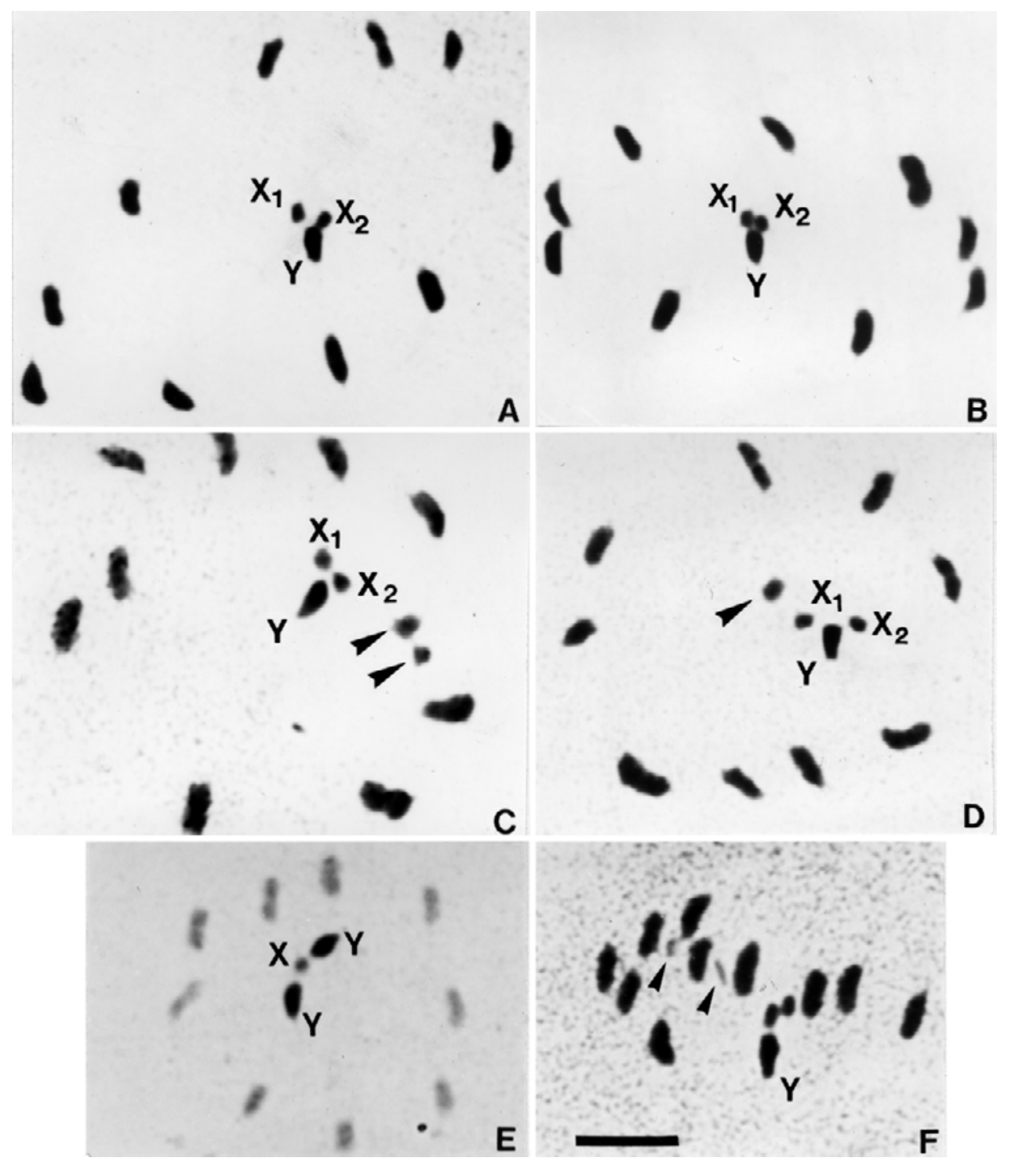

Fig. 4. Mepraia gajardoi. Different types of second metaphase plates observed in the mutant individual (male). C-banding technique. $\mathrm{Bar}=10 \mu \mathrm{m}$. A - Ten half bivalents with typical ring-shape configuration. Sex chromatids (two Xs and one Y) are associated and localized in the centre of the autosomal ring. B - Only nine half bivalents around the sex chromatids. C-D). These plates have nine half bivalents and two (C) or one (D) univalent (single chromatids) (arrowheads). The univalents are positioned close to the sex chromosomes. $\mathrm{E}$ - This plate has nine half bivalents, two $\mathrm{Y}$ and one $\mathrm{X}$ chromosome. $\mathrm{F}$ - In addition to ten half bivalents and three sex chromosomes there are two small fragments of chromosome (arrowheads).

formed by the association of the three sex chromosomes (Fig. 1). These cytogenetic traits are different from those of Mepraia spinolai. This latter species has large heterochromatic regions on all chromosomes, including both Xs (Schofield et al., 1998; Frías \& Atria, 1998) and a distinctive meiotic chromocenter formed by the association of the heterochromatic regions of some autosomes with the three sex chromosomes (Panzera et al., 1998). These striking cytogenetic differences between M. spinolai and M. gajardoi are additional support for regarding them as separate species.

\section{Chromosomal arrangement in $M$. gajardoi}

In this paper, a structural rearrangement of the holocentric chromosomes of the subfamily Triatominae is described for the first time. During meiosis and mitosis, one of the eleven individuals studied underwent a simple unequal translocation between two non-homologous medium sized chromosomes, in which the break points were located near the telomeric region. The result of this translocation was one large and two smaller chromosomes plus two telomeric chromosomal fragments (Fig. 2). The telomeric "sticky ends" of the chromosomal fragments probably tended to adhere to one another to produce a single chromosomal fragment. Since this chromosomal rearrangement was observed in all meiotic 
cells and in gonial mitosis it most probably occurred before germinal cell development.

We assume that the trivalent observed during the first meiotic division is formed by the association of the fused chromosome with its two smaller partners (Figs 3A-D). The formation of the trivalent implies changes in the recombination process and formation of chiasma. It is assumed that Heteroptera usually have only one chiasma per bivalent (Ueshima, 1979; Manna, 1984). This is characteristic of other species of Triatominae (Pérez et al., 1997) as well as of the bivalents of the individuals of $M$. gajardoi studied here. However, the formation of a meiotic trivalent requires the occurrence of two chiasmata since each of the smaller chromosomes need one chiasma in order for them to remain connected to the larger fused chromosome up to first metaphase (Fig 3A). As a consequence, it is likely that the autosomal univalents observed during first metaphase were produced by a failure in chiasma formation. If only one chiasma occurs between the large chromosome and one of the small chromosome, the trivalent is replaced by a heteromorphic bivalent and a univalent (Fig. 3E). If there are no chiasmata then the trivalent will be replaced by three univalents (Fig. 3F).

Segregation of trivalent and univalent chromosomes during meiosis is particularly characteristic. Segregation of the trivalent at first anaphase is regular: two chromosomes to one pole and one to the other (Fig. 3D). The same regular $1: 2$ separation is also observed in a hybrid between two species of Cimex (Cimicidae: Heteroptera), which indicates that reductional segregation is a common feature of holocentric trivalents (Ueshima, 1963). This kind of segregation explains most of the variation in chromosomal complement at second metaphase, particularly those with ten or nine half-bivalents (Figs 4A and 4B, respectively). Segregation of univalents at first anaphase is also very characteristic and the likely cause of the other abnormalities observed on second metaphase plates. In organisms with holocentric chromosomes, univalent segregation at first division can be reductional (Nokkala, 1986a) or, more commonly equational (Bressa et al., 2001). The large proportion of univalents (single chromatids) observed at the second metaphase strongly suggests that first metaphase univalents segregate equationally, i.e. chromatids go to different poles. At first metaphase, the univalents are close to (Fig. 3F) and segregate with the sex chromosomes. This behaviour causes the univalent chromatids to appear in second metaphase together with the sex chromosomes, resembling a sex mechanism with extra $X$ chromosomes (Figs 4C, D). As observed in other organisms (Nokkala, 1986b), the segregation of univalents in organisms with holocentric chromosomes can also influence the segregation of other autosomes and sex chromosomes. The proximity of sex chromatids and autosomal univalents during anaphase can lead to failures in segregation, producing some of the anomalies observed on the second metaphase plates, for example, cells with two Y chromosomes (Fig. 4E) or with a variable number of autosomes (Table 1).

\section{Behaviour of chromosomal fragments}

The chromosomal fragments in M. gajardoi are a byproduct of translocation (Fig. 4F) since they were not seen in normal individuals. In species with localized centromeres acentric fragments are lost during cell division. But this does not apply to organisms with holocentric chromosomes, in which chromosome fragments are potentially able to form spindle attachments and migrate autonomously to the poles during anaphase. The fragments in M. gajardoi were observed up to second metaphase in some cells, but as segregation is irregular the number is variable as they are even absent in some mitotic and meiotic cells (Figs 3C, 4F). Although holocentric, small fragments have difficulty segregating during cell divisions and they may eventually be lost from the cells. During mitosis, kinetochore plates in holocentric chromosomes extend along most of the length of a chromatid, which account for the holokinetic behaviour. In some organisms the kinetochore does not reach the telomere but occupies around $75 \%$ of the chromosome (Comings \& Okada, 1972). Hence, it is likely that many telomeric fragments are devoid of kinetochore plates, which explains their loss from some mitotic cells. Lack of kinetochore plates is not a limitation in meiosis because during this division the kinetochore fibres attach directly to the chromatin and not via a differentiated kinetochore region. However, these fragments also seem to be lost during meiosis since at the second metaphase there were less than a half of those detected at the first metaphase (19\% against $40 \%)$. It is possible that for segregation holocentric chromosomes need to be a minimum size, which assures their correct orientation for segregation.

The behaviour of chromosomal fragments resembles that of B chromosomes in other organisms. Supernumerary or B chromosomes are extra chromosomes that may vary in number among members of the same population and even different cells of the same individual (Camacho et al., 2000). B chromosomes originated as chromosomal remnants of structural rearrangements and might become as large as other chromosomes by repeated duplication (White, 1973). According to this hypothesis the chromosomal fragments in M. spinolai are potential neo-B chromosomes, which may eventually become wide spread in populations of this species if they become stabilized and positively selected for. Because of their holokinetic nature, holocentric chromosome fragments should be more easily stabilized. However, it seems that B chromosomes are strongly selected against since they are not common in triatomines. One possible explanation is that chromosomal fragments, as univalents, can affect the segregation of other chromosomes. The numerous changes in segregation at second metaphase observed in the mutant individual in this study (Table 1) could be due to the chromosomal fragments interfering with the segregation of the regular chromosomal complement.

\section{Chromosomal evolution in Triatominae}

Heteroptera show dissimilar levels of chromosomal variability (Ueshima, 1979). The subfamily Triatominae 
is characterized by a high degree of chromosomal homogeneity, particularly in the number of autosomes. All of the 70 species studied have 20 autosomes, except for three: Triatoma rubrofasciata with 22 autosomes, and Panstrongylus megistus and T. nitida both with 18 (Dujardin et al., 2002). It is suggested that 20 autosomes is the primitive number of this group and that fissions and fusions have resulted in species with 22 and 18 autosomes, respectively (Ueshima, 1966, 1979). In this subfamily there are three sex chromosome determining systems in males: $\mathrm{XY}, \mathrm{X}_{1} \mathrm{X}_{2} \mathrm{Y}$ and $\mathrm{X}_{1} \mathrm{X}_{2} \mathrm{X}_{3} \mathrm{Y}$. It is suggested that $\mathrm{XY}$ is primitive and that the other mechanisms were produced by fragmentation of the original $\mathrm{X}$ chromosome. Our results indicate that fusion can result in a diminution in the autosomal number in Triatominae. In addition, the mutant individual studied generated gametes with variable number of autosomes and sex chromosomes, which account for the whole range of chromosomal variation detected in this subfamily. Thus, autosomal fragmentation is not only a way to increase the numbers of autosomes but also sex chromosomes in triatomines. This has to be taken into account when analysing chromosomal evolution in this subfamily, particularly that of the sex chromosomes. The variability in size and staining of the $\mathrm{X}$ chromosomes of different species with multiple sex mechanisms suggest that both fragmentation of sex chromosomes (as suggested by Ueshima, 1966) and autosomal rearrangements were involved in their origin (Panzera et al., 1998).

The relative homogeneity of the chromosomal complement of the Triatominae seems to indicate that chromosomal rearrangements are not very common in this subfamily. The holocentric nature and the different behaviour of autosomes and sex chromosomes in triatomines results in malfunctioning chromosomes in individuals with rearrangement, which increases the number of non viable gametes. In this context, Mepraia species could be rather unusual. Recently, Frías \& Atria (1998) found a population of $M$. spinolai polymorphic for a small sex chromosome. They suggested that this polymorphism resulted from the fragmentation of the original $\mathrm{Y}$ chromosome and is associated with the exceptional alary polymorphism in this genus. The polymorphic sex chromosomes are only present in some cells and can affect the normal segregation of the other sex chromosomes. This latter behaviour resembles that of the univalents and chromosomal fragments of the mutant individual here studied. It is possible that this extra sex chromosome originated from chromosomal remnants of a translocation event, which stabilized in the population. The sex chromosome polymorphism in $M$. spinolai, together with our results for M. gajardoi suggests that the genus Mepraia is more prone to experience chromosomal rearrangements than other members of the subfamily Triatominae. This apparent chromosome instability, together with alary polymorphism, make Mepraia an interesting genus within the Triatominae. The analysis of a larger number of individuals and new populations will improve our under- standing of the importance of rearrangement in the evolutionary history of the genus Mepraia.

ACKNOWLEDGEMENTS. This work was partially supported by CSIC, PEDECIBA and CONICYT (Fondo Clemente Estable, Project 2034) in Uruguay. Commission of the European Communities (ECLAT and EUSAPH networks and CDIA-ICA4-CT2003-10049-project) provided additional financial support. The observations and photographs were mostly made on NIKON photomicroscopes donated by the Government of Japan. We appreciate very much the collaboration of N. García Díaz, V.P. Peña and J. Mont of the department of environmental health of Arica. We wish to thank C. Schofield (coordinator for ECLAT research network) for critical reading of this manuscript.

\section{REFERENCES}

Bressa M.J., Papeschi A.G., Mola L. \& Larramendy M.L. 1998: Meiotic studies in Largus rufipenis (Castelnau) (Largidae, Heteroptera). II. Reciprocal traslocation heterozygosity. Caryologia 51: 253-264.

Bressa M.J., Papeschi A.G., Mola L. \& Larramendy M.L. 2001: Autosomal univalents as a common meiotic feature in Jadera haematoloma and Jadera sanguinolenta (Heteroptera: Rhopalidae: Serinethinae). Eur. J. Entomol. 98: 151-157.

Camacho J.P., Sharbel T.F. \& Beukeboom L.W. 2000: B-chromosome evolution. Philos. Trans. R. Soc. Lond. (B) (Biol. Sci.) 355: 163-178.

Comings D.E \& OKadA T.A. 1972: Holocentric chromosomes in Oncopeltus: kinetochore plates are present in mitosis but absent in meiosis. Chromosoma 37: 177-192.

Dujardin J.P., Schofield C.J. \& Panzera F. 2002: Los Vectores de la Enfermedad de Chagas. Académie Royale des Sciences d'Outre-Mer, Classe des Sciences naturelles et médicales N.S., 25 (3), Bruxelles, 189 pp.

FriAs D. \& ATRIA J. 1998: Chromosomal variation, macroevolution and posible parapatric speciation in Mepraia spinolai (Porter) (Hemiptera: Reduviidae). Genet. Mol. Biol. 21(2): 179-184.

Frias D.A., Henry A.A. \& GonzÁlez C.R. 1998: Mepraia gajardoi: a new species of Triatominae (Hemiptera: Reduviidae) from Chile and its comparison with Mepraia spinolai. Rev. Chil. Hist. Nat. 71: 177-188.

Hughes-Schrader S. \& Schrader F. 1961: The kinetochore of the Hemiptera. Chromosoma 12: 327-350.

Jurberg J., Lent H., Carcavallo R.U., Silva Rocha D., Galvão C. \& Frías Lasserre D. 2002: Estudo morfológico da genitalia externa masculina de Mepraia gajardoi Frias, Henry \& Gonzalez 1998, (Hemiptera. Reduviidae) com comentarios sobre suas relaçoes filogenéticas. Entomol. Vect. 9: 559-577.

ManNA G.K. 1984: Chromosomes in evolution in Heteroptera. In: A.K. Sharma A. \& Sharma A. (eds): Chromosomes in Evolution of Eukaryotic groups. No. 2. CRC Press, Florida, pp. 189-225.

NOKKALA S. 1986a: The mechanisms behind the regular segregation of the $\mathrm{m}$-chromosomes in Coreus marginatus L. (Coreidae, Hemiptera). Hereditas 105: 73-85.

NokKaLA S. 1986b: The meiotic behaviour of B-chromosomes and their effect on the segregation of sex chromosomes in males of Hemerobius marginatus L. (Hemerobidae, Neuroptera). Hereditas 105: 221-227.

Panzera F., Alvarez F., Sanchez-Rufas J., Pérez R., Suja J., Scrortzoff E., Estramil E., Dujardin J.P. \& Salvatella R. 1992: C-heterochromatin polymorphism in holocentric chromosomes of Triatoma infestans (Hemiptera-Reduvidae). Genome 35: 1068-1074. 
Panzera F., Pérez R., Panzera Y., Alvarez F., Scvortzoff E. \& Salvatella R. 1995: Karyotype evolution in holocentric chromosomes of three related species of triatomines (Hemiptera-Reduviidae). Chromosome Res. 3: 143-150.

Panzera F., Hornos S., Pereira J., Cestau R., Canale D., Diotaiuti L., Dujardin J.P. \& Pérez R. 1997: Genetic variability and geographic differentiation among three species of triatomine bugs (Hemiptera-Reduviidae). Am. J. Trop. Med. Hyg. 57: 732-739.

Panzera F., Scvortzoff E., Pérez R., Panzera Y., Hornos S., Cestau R., Nicolini P., Delgado V., Alvarez F., Mazzella M., Cossio G., Martínez M. \& Salvatella R. 1998: Citogenetics of Triatomines. In Atlas de Triatominos de América. Chapter 15. Fundación Oswaldo Cruz (FIOCRUZ), Río de Janeiro, Brazil, pp. 621- 664.

Papeschi A.G. \& Mola L.M. 1990: Meiotic studies in Acanonicus hahni (Stal) (Coreidae, Heteroptera). II. Male Chromosome behaviour in a spontaneous inversion mutant. Genetica 81: 59-66.

Pérez R., Panzera Y., Scafiezzo S., Mazzella M., Panzera F., Dujardin J.P. \& Scvortzoff E. 1992: Cytogenetic as a tool for triatominae species distinction. Mem. Inst. Oswaldo Cruz 87: 353-361.

Pérez R., Panzera F., Page J., Suja J. \& Rufas J. 1997: Meiotic behaviour of holocentric chromosomes: orientation and segregation of autosomes in Triatoma infestans (Heteroptera). Chromosome Res. 5: 47-56.
Pérez R., Hernández M., Caraccio M.N., Rose V., Valente A., Valente V., Moreno J., Angulo V., Sandoval M., Roldán J., Vargas F., WolfF M. \& Panzera F. 2002: Chromosomal Evolution Trends of the genus Panstrongylus (Hemiptera, Reduviidae), vectors of Chagas Disease. Infect. Genet. Evol. 2: 47-56.

Schofield C.J., Apt W., Sagua H., Panzera F. \& Dujardin J.P. 1998: Alary polymorphism in Triatoma spinolai and its possible relationship with demographic strategy. Med. Vet. Entomol. 12: 30-38.

Toledo Piza S. 1944: A case of spontaneous end to end permanent union of two non homologous chromosomes in the Brazilian scorpion Tityus bahiensis accompanied by irregularities in pairing. Rev. Agric. 19: 133-147.

Ueshima N. 1963: Chromosome behaviour of the Cimex pilosellus complex (Cimicidae: Hemiptera). Chromosoma 14: 511-521.

Ueshima N. 1966: Cytotaxonomy of the Triatominae (Reduviidae: Hemiptera). Chromosoma 18: 97-122.

Ueshima N. 1979: Hemiptera II: Heteroptera. In John B. (ed.): Animal Cytogenetics 3. Insecta 6. Gebruder Borntrager, Berlin, $117 \mathrm{pp}$.

White M.J.D. 1973: Animal Cytology and Evolution. 3rd ed. Cambridge University Press, London, $961 \mathrm{pp}$.

WHO 2002: Control of Chagas Disease. Second report of the WHO Expert Committee. World Health Organization. Geneva. World Health Organ. Tech. Rep. Ser. 905: 1-109.

Received October 20, 2003; revised January 6, 2004; accepted February 2, 2004 